\title{
Determinants of Postnatal Care Use in Kenya
}

\author{
Daniel Akunga ${ }^{\mathrm{a}}$ Diana Menya ${ }^{\mathrm{b}}$ and Mark Kabue ${ }^{\mathrm{c} 1}$ \\ aKenyatta University, Department of Environmental Health, School of Public Health \\ ${ }^{b}$ Moi University, Department of Epidemiology and Nutrition, School of Public Health \\ cJhpiego, an affiliate of Johns Hopkins University, MER Unit.
}

\begin{abstract}
Pregnancy-related complications may result in maternal deaths post-delivery especially in developing countries. Skilled deliveries and postnatal care (PNC) use in Kenya is low. The objective of this study was to identify the determinants of PNC use. Kenya Demographic and Health Survey (2008-09 KDHS) women's data were analyzed. Overall data from 3,970 women were analyzed. Results indicate that 47 percent of the women received PNC services. Factors associated with PNC use are mothers' age at delivery of the last child, $4+$ ANC visits, urban residence, and skilled delivery. However, lack of education and unskilled delivery were associated with low use of PNC services $(p<0.05)$. In conclusion, the use of PNC services is low at 47 percent although the main determinants for PNC use are amenable to intervention. Strengthening of maternal health services throughout the continuum of care and promoting the use of high-quality services by pregnant women is recommended.
\end{abstract}

Keywords: Maternal health, skilled delivery, postnatal care, antenatal care

\section{Résumé}

Les complications apparentées a la grossesse peuvent résulter au décès maternel après naissance plus particulièrement dans les pays en voie de développement. L'utilisation des services d'accouchement par personnel qualifie et les soins post natals (SPN) sont d'un niveau bas au Kenya. Identifier les déterminants de l'utilisation des SPN était le but de cette étude. Les données de l'étude démographique et sanitaire des femmes du Kenya (KDHS 2008-09) ont été analysées. Les données de 3700 femmes ont fait l'objet de cette analyse. Les résultats indiquent que 47 pourcent ont reçus les services SPN. Les facteurs associés à l'utilisation des services SPN sont ; les mères qui donne naissance de leurs dernier enfant dans la tranche d'âge de 30-39, plus de quatre(4) visites anti natales, résidence dans les milieux urbains, et l' accouchement par personnel qualifié. Toutefois, la non scolarisation, et l'accouchement en absence de personnel qualifié sont associes au manque d'utilisation des SPN $(p<0.05)$. En conclusion, l'usage des SPN est faible soit 47 pourcent même si les déterminants de l'utilisation de SPN sont du ressort de l'intervention. Le renforcement des services de santé maternelle pour promouvoir l'accouchement par personnel qualifié tout au long du continuum des soins et promouvoir l'usage des services de haute qualité par les femmes enceintes.

Mots clés: santé maternelle, accouchement par personnel qualifié, soins post natals, soins anti natals 


\section{Introduction}

Postnatal care (PNC) includes services provided to women and newborns immediately after delivery and up to six weeks thereafter, with the aim of ensuring optimum health for both mothers and their infants. Lack of adequate PNC could result in poor maternal health outcomes for both the mother and the newborn. According to the 2008-2009 Kenya Health and Demographic Survey (KHDS), only 47\% of women received PNC [KDHS, 2008-09]. This is unacceptably low in view of the fact that worldwide most pregnancy complications leading to maternal deaths occur in developing countries such as Kenya. In this study, KDHS (2008-09) data were analysed to determine factors associated with use of postnatal care. Following the Andersen behavioral model framework [Andersen, 1995] for health services use, Young's health service utilization model was adapted and modified for this study [Young and YoungGarro, 1982]. This allowed for identification of factors that are amenable to intervention aimed at improving PNC use and thus contributing to the reduction of the high maternal mortality and morbidity rates in mothers in Kenyan women.

\section{Literature review and framework}

Postnatal care (PNC) is an important aspect of maternal and newborn care. Access to high-quality care provided by skilled attendants significantly improves maternal health, because it allows for early detection of problems that could result in adverse pregnancy outcomes [de Bernis et al., 2003]. Worldwide, more than 500,000 women die annually from complications related to pregnancy. About 60 percent of maternal deaths occur within the first 48 hours of delivery. Most of the deaths occur in developing countries, and most are due to postpartum hemorrhage [WHO and World Bank, 2008]. Other common poor maternal outcomes include infection, uterine rupture, dystocia, and eclampsia [Rosmans and Graham, 2006]. Kenya's maternal mortality rate of 590 per 100,000 live births in 1998, 414 in 2002[KDHS, 2003] and 480 reported in the KDHS 2008-09 is unacceptably high.

Antenatal care (ANC) has improved over time because of interventions, while PNC still lags behind in many parts of the developing world. Recognition of the importance of PNC in the continuum of care for mothers, from pregnancy through delivery and post-delivery period, has resulted in implementation of policies aimed at improving maternal and newborn health. In Kenya it is now recommended that mothers should have at least four ANC visits, should deliver in a health facility under skilled attendance, and should have four targeted PNC visits.

Poor maternal health outcomes are caused by a combination of factors, including the level and quality of health services and the health-seeking behavior of mothers. In Kenya, over 80 percent of health facilities have the capacity to offer an adequate maternal health package through the continuum of care [KSPA, 20II]. Levels of ANC use (at least one visit) are appreciably high at 92 percent [KDHS, 2008-09]. Furthermore, health programs targeting pregnant women are available. However only $40 \%$ of deliveries were assisted by a health professional in 2003 [KDHS, 2003] and 43\% in 2008 [KDHS, 200809].This is unacceptably low. PNC utilization is also very low in Kenya at 47 percent, as it is in other developing countries, such as Nepal and Tanzania [Dhakal et al., 2007; Neupane and Doku, 2013; Mwifadhiet al., 2009; Matijasevich et al. 2009], despite availability of the service. In Nigeria, it was even lower at $41.2 \%$ according to its 2005 National HIV/AIDS and Reproductive Health Survey [Babalola and Fatusi, 2009].

A study on determinants of postnatal care, using DHS data from 30 developing countries, showed that 50 percent of all births occurred outside a health facility [Forte et al., 2006]. Worse still, in 70 percent of deliveries with skilled attendants, the mothers did not receive any PNC. Rural residence, low levels of education, low wealth index, and poor or no antenatal care (ANC) were identified as key factors associated with non-use of PNC. From the 2008 Nigerian DHS data, residence in communities with a high proportion of educated women and a high level health facility delivery was associated with the likelihood of receiving PNC [Ononokpono et al., 20/3]. In Pakistan, low utilization of PNC was associated with low level of education, low socioeconomic level and rural poor residence [Yunus et al., 20I3]. Non-DHS data also show that rural residence, home deliveries and living more than five kilometres to health facilities is associated with low PNC utilization. As well cultural practises such as seclusion until the umbilical cord falls off [Pomerai et al., 2012] have been identified.

With modifications from Anderson's behavioural model [Anderson, 1995], the current paper is based on Young's 1982 choice-making model of health services utilization (Figure I). Postnatal care service utilization by pregnant mothers in Kenya is a function of four components as identified by Young. First are perceptions of gravity. This includes how preg- 
nant mothers perceive health outcomes upon delivery and their social network's consideration of postdelivery complications. Indeed postpartum complications for most communities in Kenya are a cultural issue. Second is the knowledge of a home treatment in the form of a traditional birth attendant (TBA). Most pregnant mothers in Kenya are delivered by a TBA whom they perceive as friendly and efficacious. Hence these mothers usually utilize this form of service before utilizing a professional health care system. In most cases this homemade remedy is based on lay referral. Third is the faith the pregnant mothers have on their trusted TBA. Here the mother believes in the efficacy of postnatal care service after delivery. Fourth is ease of accessibility of treatment both with regard to cost and availability of the postnatal services. Indeed according to Young, access to postnatal services is the most important influence on health care utilization [Wolinsky, 1988; Sauvain-Dugerdil, $\mathrm{C}$ and Hill, 20I4].

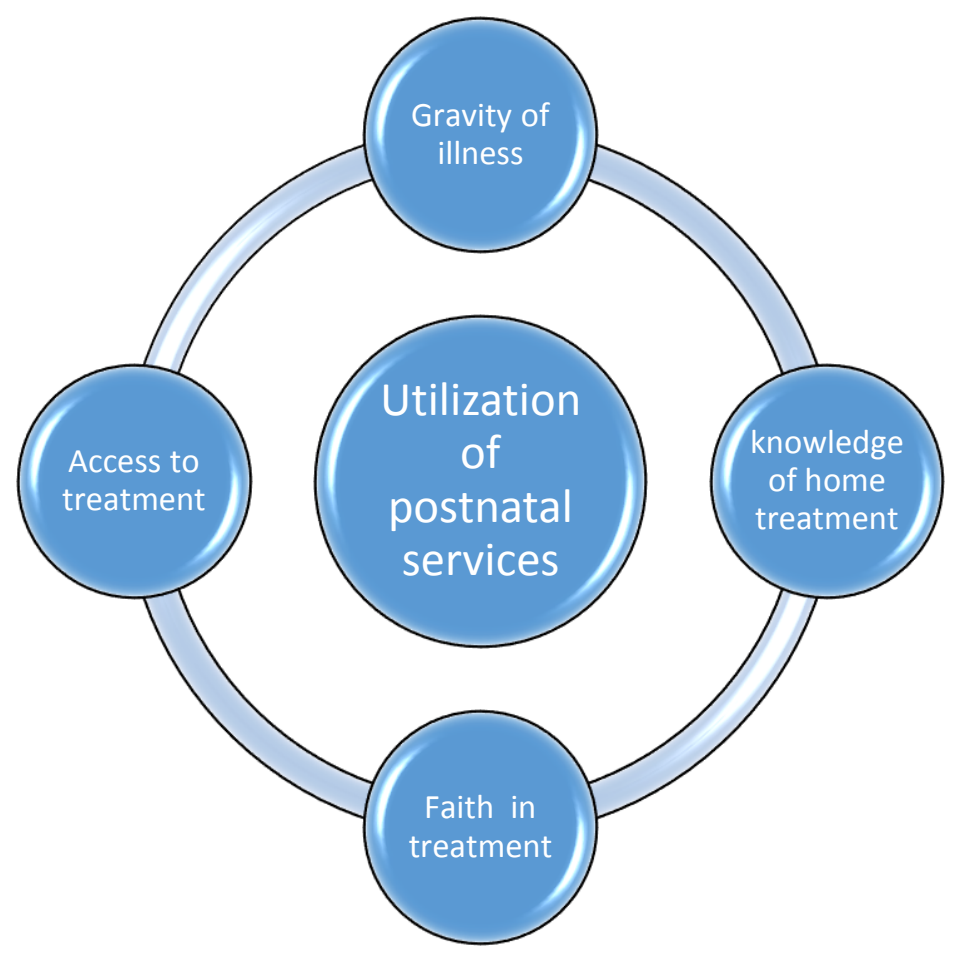

Figure I: Health Utilization Choice-Making Model, adapted and modified from Young, 1982.

In this paper, the term PNC is used to denote care related to the mother only and not to the newborn. Information regarding factors that inhibit effective use of PNC services in Kenya is not well documented hence the need for this study using nationally representative data to provide reliable information that will inform policy related to maternal health.

\section{Data and methods}

\section{Study design and data sources}

The study was conducted using nationally representative data from the KDHS 2008-09. DHS surveys are cross-sectional in design, are populationbased and are commonly sampled using a multistage stratified sampling strategy in which women of reproductive age (15-49) and men age 15-54 are interviewed separately [KDHS, 2008-09].

This paper analyses data collected using the women's questionnaire, which asks about women's demographic characteristics, reproductive history, pregnancy history (number of children, birth inter- val, weight of child, wantedness of child) and postnatal care. The sub-population analyzed in this study are women who reported having a live birth in the five-year period preceding the survey. The sampling method of the KDHS has been reported in detail elsewhere [KDHS, 2008-09].

The dependent variable, PNC use, was categorized into whether or not women received postpartum care, irrespective of the skill of the provider. Eighteen explanatory variables were placed into three major groups: mother's characteristics, pregnancy history and health service provision factors. It's noteworthy that although past DHS surveys provided PNC information only for births that occurred outside health facilities, current DHS surveys collect postnatal care information for all births, whether delivered in health facilities or elsewhere [Forte et al., 2006].

In the KDHS 2008-09, a representative sample of 8,444 households participated in the survey. The sampling followed mathematically derived weights 
for regional representation. The KDHS survey involved all women age 15-49 who were either usual residents (de jure) or visitors present in selected households on the night before the survey (de facto).

\section{Variables}

The dependent variable, PNC use, was measured based on whether a woman was checked by someone after delivery, irrespective of place of delivery and skill of the person checking her health. If this checking was reported to have occurred after 42 days since delivery, then this was treated as receiving no PNC.

Several independent variables were used to predict PNC use. These include: skill of ANC provider, skill of delivery provider, birth interval, and age of mother at the time of her last birth. The process involved combining several individual variables into distinct categories. Skill of ANC provider was categorized into doctor, nurse/midwife and unskilled. If a woman saw more than one ANC provider, the provider with the highest qualification was considered. Skill of delivery provider was categorized into skilled and unskilled (skilled if the provider has a formal training in midwifery and these included nurses, clinical officers and doctors and unskilled if the provider has no formal training in midwifery including traditional birth attendants), while age of mother at the time of her last birth was calculated based on the current age of child. The mother's age was then grouped into four categories namely; below 20, 20 $29,30-39$, and 40 and above years. Other independent variables considered were religion, marital status, residence, region, wealth index, level of education of mother, whether pregnancy for last child was wanted or not, size of baby, number of children ever born, weight of baby, birth interval of the preceding child, whether the mother was told about pregnancy complications during ANC, number of ANC visits and place of delivery. It is worth noting that in the ideal situation, the skill of ANC provider and skill of delivery provider will be highly correlated.

\section{Statistical analysis}

Bivariate and multivariate analyses were done using SPSS version 18.0. First, descriptive statistics were done, and then the association between independent variables and PNC use was tested using Pearson's chi-square. Because the chi-squared analysis indicates associations of the selected variables without controlling for the confounding effects of other variables, the net effects of each independent varia- ble were further examined using multivariate logistic regression analysis at the $95 \%$ confidence interval [Sauvain-Dugerdil, C and Hill, 20I4; Tawiah, 20I I].

To take care of multicollinearity of two or more predictor variables two regression models are explored in this paper. Both models control for the effects of age of mother at birth of last child, marital status, wealth index, level of education, region, residence, religion, whether youngest child was wanted, number of children ever born, number of ANC visits, place of delivery, birth interval of preceding child, skill of ANC provider and skill of delivery provider. In this paper our interest is to know what determines PNC use among pregnant women in Kenya. The data here is the number of women respondents in the KDHS, 2008-09 data set who reported use of PNC services. Using a binomial function, $\mathrm{f}(\mathrm{x} / \mathrm{p})$ given by:

$$
f(x / p)=\left(\begin{array}{l}
n \\
x
\end{array}\right) p^{x}(1-p)^{n-x} l(x \in\{0,1,2, \ldots \ldots n\})
$$

Where $n=$ number of women interviewed for PNC use while $p$ in this model encodes our theory about the proportion of women using PNC in Ken$y a$. Considering all possibilities for $p$ our statistical model for PNC use $X$ becomes:

$$
\{\operatorname{Bin}(n, p): p \in\{0,1\}\} \text {. }
$$

Initial analysis showed that birth interval of preceding child had a strong correlation with number of children ever born. Skill of ANC provider was correlated to number of ANC visits. Similarly skill of delivery provider was shown to be strongly related to place of delivery. Hence the two models to eliminate possibility of multicollinearity as demonstrated in table 3.

\section{Results}

Of the women surveyed in the KDHS, 3,973 had a birth in the five years preceding the survey. Of these about $42 \%$ delivered in the health facility while $47 \%$ reported receiving PNC services. Table I summarizes the characteristics of the women who received PNC services (both after health facility or home delivery). The majority were age 20-29 at birth of the last child, were married or living together and lived in rural areas. About $90 \%$ had at least primary school education, and $68 \%$ were Protestant. Sixty percent had parity of three or less. About half had a birth interval of 24-59 months for the preceding 
child. Forty-seven percent reported that they would have preferred to have the last child either later or not at all. Only $40 \%$ were told about signs of pregnancy complications during ANC visits, and over $90 \%$ reported attending ANC at least once, with those who attended four or more visits accounting for $47 \%$. Over $90 \%$ of women were attended to by a skilled provider during ANC, primarily a nurse or midwife. Nearly half of women delivered in a health facility, while $52 \%$ delivered at home (Table I).

Table I: Characteristics of women age 15-49 with at least one birth in the five years preceding the survey, KDHS 2008-09

\begin{tabular}{|c|c|c|}
\hline & Percentage & Number of Mothers \\
\hline \multicolumn{3}{|c|}{ Whether received PNC services (outcome variable) } \\
\hline Received PNC services & 52.6 & 1882 \\
\hline Did not receive PNC services & 47.4 & 2091 \\
\hline Total & 100.0 & 3973 \\
\hline \multicolumn{3}{|l|}{ Background characteristics } \\
\hline \multicolumn{3}{|c|}{ Age of the mother at the time of delivery } \\
\hline Below 20 & 14.2 & 564 \\
\hline $20-29$ & 55.5 & 2206 \\
\hline $30-39$ & 25.8 & 1025 \\
\hline 40 and above & 4.5 & 178 \\
\hline \multicolumn{3}{|l|}{ Current marital status } \\
\hline Never married & 9.4 & 372 \\
\hline Widowed/Separated/Divorced & 9.0 & 356 \\
\hline Married/Living together & 81.7 & 3245 \\
\hline \multicolumn{3}{|l|}{ Type of place of residence } \\
\hline Urban & 20.7 & 823 \\
\hline Rural & 79.3 & 3150 \\
\hline \multicolumn{3}{|l|}{ Province of residence } \\
\hline North Eastern & 2.4 & 97 \\
\hline Western & II.I & 442 \\
\hline Rift Valley & 27.8 & 1103 \\
\hline Nyanza & 18.4 & 733 \\
\hline Eastern & 15.9 & 630 \\
\hline Coast & 8.3 & 330 \\
\hline Central & 9.3 & 371 \\
\hline Nairobi & 6.8 & 269 \\
\hline \multicolumn{3}{|l|}{ Highest level of education } \\
\hline No education & $1 \mathrm{II}$ & 441 \\
\hline Primary & 62.6 & 2486 \\
\hline Secondary + & 26.3 & 1045 \\
\hline \multicolumn{3}{|l|}{ Wealth index } \\
\hline Poorest & 21.2 & 843 \\
\hline Poorer & 19.2 & 764 \\
\hline Middle & 18.7 & 742 \\
\hline Richer & 19.3 & 765 \\
\hline Richest & 21.6 & 859 \\
\hline \multicolumn{3}{|l|}{ Religion } \\
\hline Roman Catholic & 20.6 & 820 \\
\hline Protestant & 67.9 & 2698 \\
\hline Muslim & 8.0 & 318 \\
\hline No religion/Other/Missing & 3.4 & 137 \\
\hline \multicolumn{3}{|c|}{ Mother's and child's characteristics } \\
\hline \multicolumn{3}{|l|}{ Number of children ever born } \\
\hline $\mathrm{I}^{1}$ & 21.3 & 847 \\
\hline 2 & 21.3 & 845 \\
\hline 3 & 17.3 & 686 \\
\hline $4+$ & 40.1 & 1595 \\
\hline \multicolumn{3}{|c|}{ Size of last child, according to mother } \\
\hline Large & 32.4 & 1287 \\
\hline Average & 51.8 & 2061 \\
\hline Small & 15.3 & 607 \\
\hline DK/Missing & $(0.5)$ & 18 \\
\hline
\end{tabular}




\begin{tabular}{|c|c|c|}
\hline & Percentage & Number of Mothers \\
\hline \multicolumn{3}{|c|}{ Weight of last child at birth } \\
\hline Not weighed & 48.5 & 1926 \\
\hline Below 2500 grams & 2.8 & 111 \\
\hline $2500-6500$ grams & 48.7 & 1936 \\
\hline \multicolumn{3}{|c|}{ Pregnancy for youngest child was wanted } \\
\hline Wanted then & 52.9 & 2101 \\
\hline Wanted later & 26.6 & 1056 \\
\hline Not wanted at all ${ }^{2}$ & 20.5 & 816 \\
\hline \multicolumn{3}{|c|}{ Birth interval of preceding child } \\
\hline No prior birth ${ }^{3}$ & 21.5 & 854 \\
\hline Less than 24 months & 15.6 & 621 \\
\hline 24-59 months & 47.9 & 1903 \\
\hline More than 59 months & 14.9 & 594 \\
\hline \multicolumn{3}{|c|}{ Told about complications during ANC } \\
\hline Not told & 52.2 & 2074 \\
\hline Told & 40.2 & 1597 \\
\hline No ANC/Missing/DK ${ }^{4}$ & 7.6 & 302 \\
\hline \multicolumn{3}{|c|}{ Health service provision factors } \\
\hline \multicolumn{3}{|c|}{ Skill of ANC provider } \\
\hline No ANC/Missing ${ }^{5}$ & 7.4 & 293 \\
\hline Unskilled ANC provider & $(1.1)$ & 45 \\
\hline Nurse/Midwife & 62.6 & 2486 \\
\hline Doctor & 28.9 & 1148 \\
\hline \multicolumn{3}{|l|}{ Number of ANC visits } \\
\hline$\overline{D K}$ & 2.0 & 78 \\
\hline No visits/Missing 5 & 7.3 & 293 \\
\hline I & 4.3 & 171 \\
\hline $2-3$ & 39.2 & 1559 \\
\hline $4+$ & 47.1 & 1872 \\
\hline \multicolumn{3}{|c|}{ Skill of delivery provider } \\
\hline Unskilled $^{6}$ & 52.0 & 2067 \\
\hline Skilled & 48.0 & 1906 \\
\hline \multicolumn{3}{|l|}{ Place of delivery } \\
\hline Home & 51.9 & 2064 \\
\hline En route/Other & 1.3 & 52 \\
\hline Private health facility & 11.9 & 471 \\
\hline Public health facility & 34.9 & 1386 \\
\hline Total & 100.0 & 3973 \\
\hline \multicolumn{3}{|c|}{ Notes: Figures in parenthesis are based on small samples and should be interpreted with caution. } \\
\hline \multicolumn{3}{|c|}{${ }^{2}$ Includes one mother who did not respond to the question } \\
\hline \multicolumn{3}{|c|}{${ }^{3}$ Includes seven mothers who reported twin births; second twin of first birth is included } \\
\hline \multirow{2}{*}{\multicolumn{3}{|c|}{$\begin{array}{l}{ }^{4} \text { Includes eight mothers who did not know whether they were told about complicatio } \\
\text { who did not respond to the question } \\
{ }^{5} \text { Includes three mothers who did not respond to the question }\end{array}$}} \\
\hline & \multicolumn{2}{|c|}{${ }^{5}$ Includes three mothers who did not respond to the question } \\
\hline $\begin{array}{l}{ }^{6} \text { Includes mothers whe } \\
\text { and no one }\end{array}$ & munity healt & kers, relatives, and/or friends \\
\hline
\end{tabular}

Table 2 shows a summary of findings of chisquared analysis comparing the variation of certain factors with PNC use. The following variables were found to be associated with use of PNC services ( $p$ $<0.05$ ): age of mother at delivery of the last child, place of residence rural or urban), region of residence (province), level of education, wealth index, parity, weight of child at birth, whether the child was wanted, preceding birth interval of the last child, number of ANC visits, skill of ANC provider, told about signs of pregnancy complications during ANC, skill of delivery provider and place of delivery.

Table 3 shows results of the multivariate logistic regression analysis. The predictors for PNC use were identified using two separate models. Model I excluded birth interval, skill of ANC provider and skill of delivery provider, while Model 2 excluded number of children ever born, number of ANC visits and place of delivery. 
Table 2: Postnatal care use by background characteristics among women age 15-49 who had given birth in the five years preceding the survey, KDHS 2008-09

\begin{tabular}{|c|c|c|c|}
\hline & Percent & $\mathbf{N}$ & $\chi 2$ test $P$-value \\
\hline \multicolumn{4}{|l|}{ Background characteristics } \\
\hline \multicolumn{4}{|c|}{ Age of the mother at the time of delivery } \\
\hline Below 20 & 46.2 & 564 & \multirow{5}{*}{0.011} \\
\hline $20-29$ & 48.3 & 2206 & \\
\hline $30-39$ & 48.0 & 1025 & \\
\hline 40 and above & 35.6 & 178 & \\
\hline Total & 47.4 & 3973 & \\
\hline \multicolumn{4}{|l|}{ Current marital status } \\
\hline Never married & 49.6 & 372 & \multirow{4}{*}{0.142} \\
\hline Widowed/Separated/Divorced & 42.7 & 356 & \\
\hline Married/Living together & 47.6 & 3245 & \\
\hline Total & 47.4 & 3973 & \\
\hline \multicolumn{4}{|l|}{ Type of place of residence } \\
\hline Urban & 67.8 & 823 & \multirow{3}{*}{$<0.001$} \\
\hline Rural & 42.0 & 3150 & \\
\hline Total & 47.4 & 3973 & \\
\hline \multicolumn{4}{|l|}{ Province of residence } \\
\hline North Eastern & 20.7 & 97 & \multirow{9}{*}{$<0.001$} \\
\hline Western & 40.0 & 442 & \\
\hline Rift Valley & 48.9 & 1103 & \\
\hline Nyanza & 34.2 & 733 & \\
\hline Eastern & 48.5 & 630 & \\
\hline Coast & 50.0 & 330 & \\
\hline Central & 55.8 & 371 & \\
\hline Nairobi & 81.6 & 269 & \\
\hline Total & 47.4 & 3973 & \\
\hline \multicolumn{4}{|l|}{ Highest level of education } \\
\hline No Education & 32.7 & 441 & \multirow{4}{*}{$<0.001$} \\
\hline Primary & 43.6 & 2486 & \\
\hline Secondary + & 62.7 & 1045 & \\
\hline Total & 47.4 & 3973 & \\
\hline \multicolumn{4}{|l|}{ Wealth index } \\
\hline Poorest & 35.4 & 843 & \multirow{6}{*}{$<0.001$} \\
\hline Poorer & 36.3 & 764 & \\
\hline Middle & 44.2 & 742 & \\
\hline Richer & 50.9 & 765 & \\
\hline Richest & 68.6 & 859 & \\
\hline Total & 47.4 & 3973 & \\
\hline \multicolumn{4}{|l|}{ Religion } \\
\hline Roman Catholic & 49.4 & 820 & \multirow{5}{*}{0.543} \\
\hline Protestant & 47.1 & 2698 & \\
\hline Muslim & 46.3 & 318 & \\
\hline No religion/Other/Missing & 44.1 & 137 & \\
\hline Total & 47.4 & 3973 & \\
\hline
\end{tabular}

\begin{tabular}{llll}
\hline \multicolumn{5}{l}{ Mother's and child's characteristics } \\
\hline Number of children ever born & & & \\
\hline$I^{\prime}$ & 55.7 & 847 & $<0.001$ \\
2 & 51.7 & 845 &
\end{tabular}




\begin{tabular}{|c|c|c|c|}
\hline & Percent & $\mathbf{N}$ & $\chi 2$ test $P$-value \\
\hline \multicolumn{4}{|c|}{ Background characteristics } \\
\hline 3 & 48.0 & 686 & \\
\hline $4+$ & 40.4 & 1595 & \\
\hline Total & 47.4 & 3973 & \\
\hline \multicolumn{4}{|c|}{ Size of last child according to mother } \\
\hline Large & 48.2 & 1287 & \multirow{5}{*}{0.089} \\
\hline Average & 47.5 & 2061 & \\
\hline Small & 46.0 & 607 & \\
\hline DK/Missing & $(0.5)$ & 18 & \\
\hline Total & 47.4 & 3973 & \\
\hline \multicolumn{4}{|c|}{ Youngest child Pregnancy wanted } \\
\hline Wanted then & 50.4 & 2101 & \multirow{4}{*}{$<0.001$} \\
\hline Wanted later & 45.2 & 1056 & \\
\hline Not wanted at all ${ }^{2}$ & 42.5 & 815 & \\
\hline Total & 47.4 & 3973 & \\
\hline \multicolumn{4}{|c|}{ Weight of last child at birth } \\
\hline Not weighed/Other & 26.6 & 1926 & \multirow{4}{*}{$<0.001$} \\
\hline Below 2500 grams & 72.5 & 111 & \\
\hline $2500-6500$ grams & 66.6 & 1936 & \\
\hline Total & 47.4 & 3973 & \\
\hline \multicolumn{4}{|c|}{ Birth interval of preceding child } \\
\hline No prior birth ${ }^{3}$ & 55.8 & 854 & \multirow{5}{*}{$<0.001$} \\
\hline Less than 24 months & 38.4 & 621 & \\
\hline $24-59$ months & 43.5 & 1903 & \\
\hline More than 59 months & 57.2 & 594 & \\
\hline Total & 47.4 & 3973 & \\
\hline \multicolumn{4}{|c|}{ Told about complications during ANC } \\
\hline Not told & 39.5 & 2074 & \multirow{4}{*}{$<0.001$} \\
\hline Told & 61.8 & 1597 & \\
\hline No ANC/DK/Missing ${ }^{4}$ & 25.4 & 302 & \\
\hline Total & 47.4 & 3973 & \\
\hline \multicolumn{4}{|c|}{ Health service provision factors } \\
\hline \multicolumn{4}{|l|}{ Skill of ANC provider } \\
\hline No ANC/Missing 5 & 25.0 & 293 & \multirow{5}{*}{$<0.001$} \\
\hline Unskilled ANC provider & $(52.8)$ & 45 & \\
\hline Nurse/Midwife & 46.9 & 2486 & \\
\hline Doctor & 53.9 & 1148 & \\
\hline Total & 47.4 & 3973 & \\
\hline \multicolumn{4}{|l|}{ Number of ANC visits } \\
\hline No ANC/Missing/DK 6 & 29.8 & 371 & \multirow{5}{*}{$<0.001$} \\
\hline I & 32.4 & 171 & \\
\hline $2-3$ & 40.6 & 1559 & \\
\hline $4+$ & 57.9 & 1872 & \\
\hline Total & 47.4 & 3973 & \\
\hline \multicolumn{4}{|l|}{ Skill of delivery provider } \\
\hline Unskilled $^{7}$ & 27.9 & 2067 & \multirow{3}{*}{$<0.001$} \\
\hline Skilled & 68.5 & 1906 & \\
\hline Total & 47.4 & 3973 & \\
\hline \multicolumn{4}{|l|}{ Place of delivery } \\
\hline Home & 27.7 & 2064 & $<0.001$ \\
\hline http://aps.journals.ac.za & & & \\
\hline
\end{tabular}




\begin{tabular}{|c|c|c|}
\hline & Percent & $\chi 2$ test $\mathbf{P}$-value \\
\hline \multicolumn{3}{|c|}{ Background characteristics } \\
\hline En route/Other & 42.6 & 52 \\
\hline Private health facility & 76.4 & 471 \\
\hline Public health facilities & 67.0 & 1386 \\
\hline Total & 47.4 & 3973 \\
\hline \multicolumn{3}{|l|}{ Notes: } \\
\hline \multicolumn{3}{|c|}{ Figures in parenthesis are based on small samples and should be interpreted with caution. } \\
\hline \multicolumn{3}{|c|}{ ' Excludes seven mothers who reported twin births; second twin of first birth is missing } \\
\hline \multicolumn{3}{|c|}{${ }^{2}$ Includes one mother who did not respond to the question. } \\
\hline \multicolumn{3}{|c|}{${ }^{3}$ Includes seven mothers who reported twin births; second twin of first birth is included } \\
\hline \multicolumn{3}{|c|}{${ }^{4}$ Includes eight mothers who did not know whether they were told about complications during ANC and 4 mothers who } \\
\hline \multicolumn{3}{|c|}{ did not respond to the question. } \\
\hline \multicolumn{3}{|c|}{${ }^{5}$ Includes three mothers who did not respond to the question. } \\
\hline \multicolumn{3}{|c|}{${ }^{6}$ Includes 76 who did not know whether they attended ANC and 6 missing cases. } \\
\hline \multicolumn{3}{|c|}{${ }^{7}$ Includes mothers who were delivered by traditional birth attendants, community health workers and others } \\
\hline
\end{tabular}

The results of Model I show that the odds of PNC use were $42 \%$ higher among mothers living in urban areas compared with women in rural areas, while women with no education had $30 \%$ lower odds of PNC use compared with women with secondary and/or more education, after controlling for other covariates in the model $(p<0.05)$. Women living in all other regions of the country except Rift Valley had lower odds of PNC use (4I\% to $82 \%)$ compared with women in Nairobi $(p<0.05)$, net of other covariates. Mothers who reported attending four or more ANC visits had I.84 times higher odds of using PNC services compared with mothers who did not attend ANC, net of other covariates in the model. In general, delivering in a health facility significantly increased the use of PNC services by at least $37 \%$, after controlling for other covariates in the model.
In Model 2, mothers age 30-39 at birth of last child, women living in urban areas and women receiving ANC services from either a skilled or unskilled health provider were found to be more likely to use PNC services, after controlling for other covariates $(p<0.05)$. However, having no education, residing outside of Nairobi or Rift Valley regions and being attended by an unskilled provider during delivery significantly lowered the odds of using PNC services $(p<0.05)$.

Birth interval, number of children ever born, whether the last child was wanted, wealth index, marital status and religion were not found to be predictors of PNC use in both models $(p>0.05)$, after controlling for other factors, while mother's age was a predictor only in Model 2, net of other factors (Table 3).

Table 3: Multivariate logistic regression analysis for PNC use among women age 15-49 with at least one birth in the five years preceding the survey, KDHS 2008-09

\begin{tabular}{|c|c|c|c|c|c|c|c|c|}
\hline \multicolumn{4}{|c|}{ Model I } & \multirow[b]{3}{*}{ p-value } & \multicolumn{4}{|l|}{ Model 2} \\
\hline & \multirow[b]{2}{*}{$\begin{array}{l}\text { Adj. Odds } \\
\text { ratio }\end{array}$} & \multicolumn{2}{|c|}{95 percent C.I. } & & \multirow[b]{2}{*}{$\begin{array}{l}\text { Adj. Odds } \\
\text { ratio }\end{array}$} & \multicolumn{2}{|c|}{95 percent C.I. } & \multirow[b]{2}{*}{ p-value } \\
\hline & & $\begin{array}{l}\text { Lower } \\
\text { limit }\end{array}$ & $\begin{array}{l}\text { Upper } \\
\text { limit }\end{array}$ & & & $\begin{array}{l}\text { Lower } \\
\text { limit }\end{array}$ & $\begin{array}{l}\text { Upper } \\
\text { limit }\end{array}$ & \\
\hline \multicolumn{9}{|c|}{ Age of mother at birth of last child } \\
\hline Below 20 & 1.07 & 0.68 & 1.69 & 0.761 & 1.19 & 0.77 & 1.84 & 0.434 \\
\hline $20-29$ & 1.21 & 0.82 & 1.77 & 0.338 & 1.33 & 0.92 & 1.93 & 0.132 \\
\hline $30-39$ & 1.39 & 0.96 & 2.03 & 0.085 & 1.54 & 1.06 & 2.25 & 0.025 \\
\hline 40 and Above & Reference & & & & Reference & & & \\
\hline \multicolumn{9}{|l|}{ Marital status } \\
\hline Never married & 1.14 & 0.87 & 1.50 & 0.351 & 1.09 & 0.83 & 1.43 & 0.547 \\
\hline Widowed/Separated/Divorced & 0.85 & 0.66 & 1.10 & 0.218 & 0.84 & 0.65 & 1.07 & 0.159 \\
\hline Married/Living together & Reference & & & & Reference & & & \\
\hline
\end{tabular}




\begin{tabular}{|c|c|c|c|c|c|c|c|c|}
\hline & \multicolumn{4}{|l|}{ Model I } & \multicolumn{4}{|l|}{ Model 2} \\
\hline & \multirow[b]{2}{*}{$\begin{array}{l}\text { Adj. Odds } \\
\text { ratio }\end{array}$} & \multicolumn{2}{|c|}{95 percent C.I. } & \multirow[b]{2}{*}{ p-value } & \multirow[b]{2}{*}{$\begin{array}{l}\text { Adj. Odds } \\
\text { ratio }\end{array}$} & \multicolumn{2}{|c|}{95 percent C.I. } & \multirow[b]{2}{*}{ p-value } \\
\hline & & $\begin{array}{l}\text { Lower } \\
\text { limit }\end{array}$ & $\begin{array}{l}\text { Upper } \\
\text { limit }\end{array}$ & & & $\begin{array}{l}\text { Lower } \\
\text { limit }\end{array}$ & $\begin{array}{l}\text { Upper } \\
\text { limit }\end{array}$ & \\
\hline Urban & 1.42 & 1.09 & 1.85 & 0.010 & 1.36 & 1.05 & 1.77 & .022 \\
\hline Rural & \multicolumn{3}{|l|}{ Reference } & & \multicolumn{3}{|l|}{ Reference } & \\
\hline \multicolumn{9}{|l|}{ Region } \\
\hline North Eastern & 0.18 & 0.09 & 0.38 & $<0.001$ & 0.12 & 0.06 & 0.25 & $<0.001$ \\
\hline Western & 0.59 & 0.37 & 0.92 & 0.020 & 0.53 & 0.34 & 0.82 & 0.005 \\
\hline Rift Valley & 0.85 & 0.56 & 1.28 & 0.434 & 0.75 & 0.50 & 1.13 & 0.171 \\
\hline Nyanza & 0.32 & 0.21 & 0.49 & 0.000 & 0.28 & 0.19 & 0.43 & $<0.001$ \\
\hline Eastern & 0.59 & 0.38 & 0.90 & 0.016 & 0.54 & 0.35 & 0.82 & 0.005 \\
\hline Coast & 0.49 & 0.31 & 0.77 & 0.002 & 0.44 & 0.28 & 0.69 & 0.000 \\
\hline Central & 0.52 & 0.33 & 0.81 & 0.004 & 0.46 & 0.30 & 0.72 & 0.001 \\
\hline Nairobi & \multicolumn{4}{|l|}{ Reference } & \multicolumn{3}{|l|}{ Reference } & \\
\hline \multicolumn{9}{|l|}{ Level of education } \\
\hline No education & 0.70 & 0.50 & 0.97 & 0.030 & 0.66 & 0.48 & 0.92 & 0.014 \\
\hline Primary & 0.89 & 0.74 & 1.07 & 0.219 & 0.86 & 0.72 & 1.02 & 0.088 \\
\hline Secondary + & \multicolumn{4}{|l|}{ Reference } & \multicolumn{3}{|l|}{ Reference } & \\
\hline \multicolumn{9}{|l|}{ Wealth index } \\
\hline Poorest & 1.13 & 0.83 & 1.55 & 0.430 & 1.06 & 0.78 & 1.44 & 0.716 \\
\hline Poorer & 0.91 & 0.67 & 1.22 & 0.514 & 0.83 & 0.62 & 1.12 & 0.224 \\
\hline Middle & 1.04 & 0.77 & 1.39 & 0.808 & 0.97 & 0.72 & 1.29 & 0.817 \\
\hline Richer & 0.99 & 0.76 & 1.29 & 0.926 & 0.95 & 0.73 & 1.23 & 0.706 \\
\hline Richest & \multicolumn{4}{|l|}{ Reference } & Reference & & & \\
\hline Religion & & & & & & & & \\
\hline Roman Catholic & 0.79 & 0.51 & 1.22 & 0.283 & 0.77 & 0.50 & 1.19 & 0.244 \\
\hline Protestant & 0.72 & 0.47 & 1.08 & 0.115 & 0.68 & 0.45 & 1.03 & 0.066 \\
\hline Muslim & 1.33 & 0.81 & 2.18 & 0.263 & 1.22 & 0.74 & 2.00 & 0.439 \\
\hline Other (not specified) & Reference & & & & Reference & & & \\
\hline Number of children & & & & & & & & \\
\hline $4+$ & 1.01 & 0.76 & 1.34 & 0.939 & & & & \\
\hline 3 & 0.97 & 0.74 & 1.28 & 0.847 & & & & \\
\hline 2 & 1.03 & 0.81 & 1.30 & 0.830 & Fyoluded & & & \\
\hline 1 & Reference & & & & Excluded & om Mo & & \\
\hline Birth interval of pre & & & & & & & & \\
\hline Above 59 months & & & & & 1.16 & 0.88 & 1.54 & .292 \\
\hline 24-59 months & & & & & 1.01 & 0.80 & 1.27 & .957 \\
\hline Below 24 months & & & & & 0.84 & 0.64 & 1.11 & .221 \\
\hline No prior birth & Excluded & om Moc & & & Reference & & & \\
\hline Whether child was & & & & & & & & \\
\hline Wanted then & 1.04 & 0.85 & 1.27 & 0.709 & 1.05 & 0.86 & 1.27 & 0.653 \\
\hline Wanted later & 1.05 & 0.85 & 1.30 & 0.668 & 1.07 & 0.86 & 1.33 & 0.541 \\
\hline Not wanted at all & Reference & & & & Reference & & & \\
\hline Number of ANC vis & & & & & & & & \\
\hline $4+$ & 1.84 & 1.40 & 2.42 & $<0.001$ & & & & \\
\hline $2-3$ & 1.28 & 0.97 & 1.70 & 0.077 & & & & \\
\hline I & 1.12 & 0.73 & 1.72 & 0.602 & & & & \\
\hline No ANC/Missing/DK & Reference & & & & Excluded & rom Mo & & \\
\hline Skill of ANC provid & & & & & & & & \\
\hline Doctor & & & & & 1.56 & 1.12 & 2.16 & 0.008 \\
\hline Nurse/midwife & & & & & 1.54 & 1.13 & 2.10 & 0.007 \\
\hline Unskilled & & & & & 3.45 & 1.73 & 6.86 & $<0.001$ \\
\hline No ANC/Missing & Excluded & om Moc & & & Reference & & & \\
\hline
\end{tabular}




\begin{tabular}{|c|c|c|c|c|c|c|c|c|}
\hline & \multicolumn{4}{|l|}{ Model I } & \multicolumn{4}{|l|}{ Model 2} \\
\hline & \multirow[b]{2}{*}{$\begin{array}{l}\text { Adj. Odds } \\
\text { ratio }\end{array}$} & \multicolumn{2}{|c|}{95 percent C.I. } & \multirow[b]{2}{*}{ p-value } & \multirow[b]{2}{*}{$\begin{array}{l}\text { Adj. Odds } \\
\text { ratio }\end{array}$} & \multicolumn{2}{|c|}{95 percent C.I. } & \multirow[b]{2}{*}{ p-value } \\
\hline & & $\begin{array}{l}\text { Lower } \\
\text { limit }\end{array}$ & $\begin{array}{l}\text { Upper } \\
\text { limit }\end{array}$ & & & $\begin{array}{l}\text { Lower } \\
\text { limit }\end{array}$ & $\begin{array}{l}\text { Upper } \\
\text { limit } \\
\end{array}$ & \\
\hline \multicolumn{9}{|l|}{ Place of delivery } \\
\hline Public health facility & 4.78 & 4.02 & 5.70 & $<0.001$ & & & & \\
\hline Private health facility & 6.60 & 5.06 & 8.60 & $<0.001$ & & & & \\
\hline En route/Other & 1.99 & 1.11 & 3.57 & 0.022 & & & & \\
\hline Home & \multicolumn{4}{|l|}{ Reference } & \multicolumn{4}{|c|}{ Excluded from Model 2} \\
\hline
\end{tabular}

\begin{tabular}{|c|c|c|c|c|c|}
\hline \multicolumn{6}{|c|}{ Skill of delivery provider } \\
\hline Unskilled & & 0.19 & 0.16 & 0.23 & $<0.001$ \\
\hline Skilled & Excluded from Model I & Refe & & & \\
\hline
\end{tabular}

\section{Discussion}

This study, based on a large sample size of the nationally representative DHS survey of women of reproductive age in Kenya, found that use of PNC services, at $47 \%$, is low compared with other countries in Africa and Asia [Forte et al., 2006]. In the 2008-09 KDHS, 59\% of health facilities reported the ability to adequately and effectively offer high-quality PNC services [KDHS, 2003; KSPA, 20I I] compared with $35 \%$ in 2004 . Nonetheless, the use of these services has remained low. Low use rates results in breached continuum of care for mothers and their children, which may have undesirable negative outcomes for both the women and their children, including high rates of maternal and neonatal mortality.

We identified several socio-demographic, maternal and health care delivery factors that could explain PNC use among mothers in Kenya. Our findings suggest that women with education beyond primary school, women living in urban areas, women attending at least four ANC visits and women delivering in health facilities are more likely to use PNC services compared with other women. This finding is consistent with findings from other developing countries, especially in Africa and Asia [Dhakal et al., 2009; Neupane and Doku, 2013; Mwifadhiet al., 2009; Babalola and Fatusi, 2009; Tawiah, 201 I,]. Although our analysis did not identify the number of children ever born and wealth index as determinants of PNC use, other studies have reported these two factors as determinants [Neupane and Doku, 2013].

An interesting and unexpected finding in this study is that women who received ANC services from unskilled providers had nearly four times the odds of using PNC services compared with women who did not attend ANC at all. Their odds were also higher than those who were attended to by skilled providers. Indeed the 2008-09 KDHS data shows that a higher proportion of women who received ANC services from unskilled service provider delivered at their homes. The data further indicate that a majority of those who delivered at home reported being checked for maternal outcomes by someone after delivery. The consistency of these findings may suggest that women who receive ANC services from unskilled health service providers are more likely to deliver at home and report a healthy check after delivery. This implies that unskilled health service providers are better able to retain their clients throughout the continuum of health care compared with conventional health service providers, perhaps due to proximity, familiarity, cultural considerations and/or cost. However, these findings require interpretation with caution due to small size of the subsample (49 un-weighted cases), and therefore these findings are only suggestive. A more substantive analysis that uses a large enough sample may yield more definitive information.

Another interesting finding is that women who delivered with the assistance of unskilled providers were $81 \%$ less likely to use PNC services compared with women who received skilled delivery assistance. This could possibly be explained by distance, cost, mode of transport and the notion that after delivery there may be no need for a medical checkup, since the woman is now considered to be "out of danger". Perhaps only women who developed observable complications would seek these services. However, the issues related to distance from health facility, cost and quality of service are beyond the scope of the present study.

While the findings were interesting and somewhat surprising, the fact that DHS data are cross- 
sectional is an inherent limitation in this study, as causal relationships cannot be established. In addition, although the sample size was large enough to enable the identification of the determinants of PNC use, sub-analysis to assess the relationships between the many covariates was not possible due to the small size of some of the sub-groups. For instance, we would have liked to investigate further the quality of ANC and PNC services provided in the continuum of pregnancy to delivery, but the nature of DHS data do not permit this type of analysis.

\section{Conclusions and implications}

The use of PNC services is low at $47 \%$ and hospital deliveries are also low (42\%). Our key finding was that apart from demographic factors that explain the differences in PNC use, the most important maternal health care delivery factors that influence PNC use are attending at least four ANC visits, and delivering in health facilities; these two positively related to use PNC services. These two factors are amenable to change, and it is the recommendation of the authors that programs targeting the strengthening of $\mathrm{MNCH}$ services should place special emphasis on encouraging and supporting 24-hour level two hospital deliveries [Tawiah, 2011]; strengthening effective maternal health services throughout the continuum of care and promote the use of highquality services by pregnant women in the hands of skilled providers in approved health facilities. Furthermore, the health authorities should endeavor to establish mechanisms of promoting and facilitating hospital delivery waiting services a few days before actual delivery to minimize the risk of home deliveries due to emergency labour onset that require transport to health facilities sometimes at odd hours in remote areas of Kenya.

\section{References}

Andersen, Ronald M. 1995. "Revisiting the Behavioral Model and Access to Medical Care: Does It Matter?" Journal of Health \& Social Behavior 36(I): I- 10

Babalola, S., \&Fatusi, A. (2009).Determinants of use of maternal health services in Nigeria-looking beyond individual and household factors.BMC Pregnancy and Childbirth, 9(I), 43.

Central Bureau of Statistics (CBS) [Kenya], Ministry of Health $(\mathrm{MOH})$ [Kenya], and ORC Macro. 2004. Kenya Demographic and Health Survey 2003. Calverton, Maryland, USA: CBS, $\mathrm{MOH}$, and ORC Macro.
deBernis, Luc, Della R. Sherratt, Carla AbouZahr, and Wim Van Lerberghe. 2003. "Skilled Attendants for Pregnancy, Childbirth and Postnatal Care." British Medical Bulletin 67: 39-58. doi: 10.1093/bmb/ldg017.

Dhakal, Sulochana, Glyn N. Chapman, Padam P. Simkhada, Edwin R. van Teijlingen, Jane Stephens, and Amalraj E. Raja. 2007. "Utilisation of Postnatal Care among Rural Women in Nepal."BMC Pregnancy and Childbirth 7:19. doi:10.1 186/147|-2393-7-19.

Forte, A. L., M. T. Kothari, and N. Abderrahim. 2006. Postpartum Care: Levels and Determinants in Developing Countries. Macro International: Calverton, Maryland, USA.

Kenya National Bureau of Statistics (KNBS) and ICF Macro. 2010. Kenya Demographic and Health Survey 2008-09. Calverton, Maryland, USA: KNBS and ICF Macro.

Matijasevich, Alicia, Cesar G. Victora, Jean Golding, Fernando C. Barros, Ana M. Menezes, Cora L. Araujo, and George D. Smith. 2009. "Inequities in Maternal Postnatal Visits among Public and Private Patients: 2004 Pelotas Cohort Study." BMC Public Health 9:105. doi:I0.1/86/I47I-2458-9105.

Mwifadhi Mrisho, B. O., Joanna A. Schellenberg, Rachel A. Haws, Adiel K. Mushi, Hassan Mshinda, Marcel Tanner, and David Schellenberg. 2009. "The Use of Antenatal and Postnatal Care: Perspectives and Experiences of Women and Health Care Providers in Rural Southern Tanzania."BMC Pregnancy and Childbirth 9:10.doi:10.1 I86/I47I2393-9-10.

National Coordinating Agency for Population and Development (NCAPD) [Kenya], Ministry of Public Health and Sanitation (MOPHS) [Kenya], Kenya National Bureau of Statistics (KNBS) [Kenya], and ICF Macro. 20II.Kenya Service Provision Assessment Survey, 2010. Nairobi, Kenya.

Neupane, S., \&Doku, D. (2013). Utilization of Postnatal Care Among Nepalese Women. Maternal and child health journal, I-9

Ononokpono, D. N., Odimegwu, C. O., Imasiku, E. N., \&Adedini, S. A. (2013). Does it Really Matter Where Women Live? A Multilevel Analysis of the Determinants of Postnatal Care in Nigeria.Maternal and child health journal, I-I0.

Pomerai, K. W., Shambira, G., \&Mudyiradima, R. F. (20I2). Determinants of postnatal care uptake in Bikita district, Zimbabwe. African Journal of Midwifery and Women's Health, 6(2), 84-90. 
Rosmans, C., and W. J. Graham. 2006. "Maternal Mortality: Who, When, Where, and Why." Lancet 368: $\quad$ II89-1200. doi:10.1016/S0I406736(06)69380-X

Sauvain-Dugerdil, $C$ and Hill, A.G. (20I4).The contribution of the Capability Approach to demographic analysis: Lessons learned. Tracking Inequalities. African Population Studies Vol 28, No.2 June 20I4: http://aps.journals.ac.za

Tawiah E.O. 201 I. Maternal health care in five subSaharan African countries: African Population Studies Vol 25, I (April 20II): http://aps.journals.ac.za

WHO and The World Bank. 2008. Maternal Mortality in 2005: Estimates Developed by WHO, UNICEF, UNFPA and The World Bank. Geneva, Switzerland: WHO.

Wolinsky, F. (1988b). Seeking and Using Health Services.In The Sociology of Health (2nd ed., II7144). Belmont, CA: Wadsworth.

Young, J. C., \& Young-Garro, L. Y. (1982).Variation in the Choice of Treatment in Two Mexican Communities. Social Science and Medicine, 16(16): I453-1465.

Yunus, A., Iqbal, S., Munawar, R., Zakar, R., Mushtaq, S. K., Sadaf, F., \& Usman, A. (2013). Determinants of Postnatal Care Services Utilization in Pakistan-Insights from Pakistan Demographic and Health Survey (PDHS) 2006-07. Middle-East Journal of Scientific Research, I8(I0), I440-I447.

\section{Authors' Contribution and Guarantee}

Daniel Akunga, Diana Menya and Mark Kabue participated in study design, data analysis, writing and revision of the manuscript. This manuscript is the original work of the authors' and has not been submitted to any other journal for publication.

\section{Competing interest}

Authors declare that they have no competing interests.

\section{Acknowledgments.}

We are grateful to the National Council for Population and Development (NCPD) for allowing us to publish this paper, a version of which was published as a working paper by the same organisation; also to ICF Macro for funding the authors in the further analysis of KDHS workshop in Nairobi when the draft paper was prepared. 